University of Wollongong

Research Online

Faculty of Social Sciences - Papers (Archive) Faculty of Arts, Social Sciences \& Humanities

2019

Caffeine affects children's ERPs and performance in an equiprobable go/ no-go task: Testing a processing schema

Robert J. Barry

University of Wollongong, rbarry@uow.edu.au

Frances M. De Blasio

University of Wollongong, francesd@uow.edu.au

Jack Fogarty

University of Wollongong, jf752@uowmail.edu.au

Follow this and additional works at: https://ro.uow.edu.au/sspapers

Part of the Education Commons, and the Social and Behavioral Sciences Commons

Research Online is the open access institutional repository for the University of Wollongong. For further information contact the UOW Library: research-pubs@uow.edu.au 


\title{
Caffeine affects children's ERPs and performance in an equiprobable go/no-go task: Testing a processing schema
}

\author{
Abstract \\ Caffeine's stimulant properties were used to test a proposed processing schema for children's processing \\ stages in the equiprobable auditory go/no-go task. Active control-related ERP components were \\ hypothesized to be differentially enhanced by caffeine. Caffeine $(80 \mathrm{mg})$ was administered in a \\ counterbalanced, randomized, double-blind, placebo-controlled, cross-over study of 24 children, aged 8-12 \\ years. Four blocks of an equiprobable auditory go/no-go task were completed on each of two occasions, \\ while on or off caffeine. ERP data sets from each condition (caffeine/go, placebo/go, caffeine/no-go, \\ placebo/no-go) were subjected to separate temporal PCAs with extraction and varimax rotation of all \\ components. Caffeine significantly reduced reaction time and go omission errors, and enhanced go PN, \\ N2c, and P3b, and no-go N1-1 and N2b. This selective enhancement of different go/no-go components by \\ caffeine matched the predicted amplification of biomarkers of children's active control processing in this \\ task. Some unexpected findings also support further refinements in the child processing schema.

\section{Disciplines} \\ Education | Social and Behavioral Sciences

\section{Publication Details} \\ Barry, R. J., De Blasio, F. M. \& Fogarty, J. S. (2019). Caffeine affects children's ERPs and performance in an \\ equiprobable go/no-go task: Testing a processing schema. Psychophysiology, 56 (5), \\ e13330-1-e13330-15.
}


Caffeine affects children's ERPs and performance in an equiprobable Go/NoGo task: Testing a Processing Schema

Robert J. Barry ${ }^{\mathrm{a} *}$, Frances M. De Blasio ${ }^{\mathrm{a}}$, Jack S. Fogarty ${ }^{\mathrm{a}}$

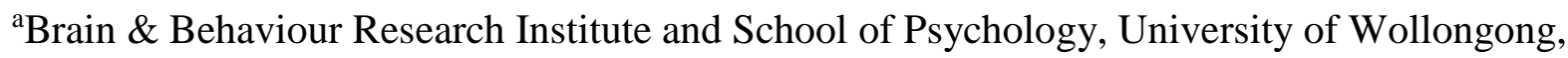
Wollongong 2522, Australia

*Corresponding author:

Phone/Fax: +612 42214421

Email: robert_barry@uow.edu.au 


\begin{abstract}
Caffeine’s stimulant properties were used to test a proposed Processing Schema for children’s processing stages in the equiprobable auditory Go/NoGo task. Active control-related ERP components were hypothesised to be differentially enhanced by caffeine. Caffeine (80 mg) was administered in a counterbalanced randomised double-blind placebo-controlled cross-over study of 24 children, aged 8-12 years. Four blocks of an equiprobable auditory Go/NoGo task were completed on each of two occasions, while on- or off-caffeine. ERP datasets from each condition (Caffeine/Go, Placebo/Go, Caffeine/NoGo, Placebo/NoGo) were subjected to separate temporal PCAs with extraction and Varimax rotation of all components. Caffeine significantly reduced RT and Go omission errors, and enhanced Go PN, N2c, and P3b, and NoGo N1-1 and N2b. This selective enhancement of different Go/NoGo components by caffeine matched the predicted amplification of biomarkers of children's active control processing in this task. Some unexpected findings also support further refinements in the Child Processing Schema.
\end{abstract}

Keywords: Child Processing Schema, Equiprobable Go/NoGo task, Principal Components Analysis (PCA), Caffeine, Cognitive Control Processes. 


\section{Introduction}

For several years, the unwarned auditory Go/NoGo task has been used as a vehicle to explore the ERP markers of the brain's cognitive control processes. This is a simple two-choice task, where one (Go) stimulus requires an active response (usually a button-press), and the other (NoGo) does not, involving inhibition of the prepared Go response. The equiprobable variant of this task is perhaps the most common (Wessel, 2018), and is efficient in providing equal numbers of trials forming the Go and NoGo ERPs. A downside of this paradigm, however, is that the inhibitory requirements are not maximal (Wessel, 2018). Indeed, Barry and Rushby (2006) considered that no active inhibition was required in the equiprobable task, but other studies have demonstrated a link between NoGo N2b in this task and reduced commission errors (e.g., Falkenstein, Hoormann, \& Hohnsbein, 1999; Fogarty, Barry, De Blasio, \& Steiner, 2018), particularly in children, who find inhibition in the task more difficult than do adults (Barry, De Blasio, \& Fogarty, 2018).

The bulk of the Go/NoGo ERP literature has examined the N2-P3 complex in relation to the cognitive control required to adequately complete the task - selectively responding to the Go stimulus and withholding that response from the NoGo stimulus (e.g., Falkenstein et al., 1999; Smith, Johnstone, \& Barry, 2006). The NoGo condition is associated with enhanced frontal N2 and a more central P3 than is found for Go. Although these were originally considered to directly reflect response inhibition (e.g., Falkenstein et al., 1999; Pfefferbaum, Ford, Weller, \& Kopell, 1985), recent work suggests they may rather reflect stimulus- or response-conflict (e.g., Botvinick, Braver, Barch, Carter, \& Cohen, 2001; Donkers \& van Boxtel, 2004; Huster, Enriquez-Geppert, Lavallee, Falkenstein, \& Herrmann, 2013; Nieuwenhuis, Yeung, van den Wildenberg, \& Ridderinkhof, 2003). These different interpretations can be explored in modified Go/NoGo tasks (e.g., Enriquez-Geppert, Konrad, Pantev, \& Huster, 2010), but the broad “inhibition” link is retained here for convenience.

Relatively few studies focus on a wider range of components in the ERPs of the Go/NoGo task, but Pires, Leitão, Guerrini, and Simões (2014) reviewed inhibition/control effects in a variety of tasks, and reported that NoGo enhancements in P1, N1, N2, and P3 can occur in the Go/NoGo task. A Processing Schema to conceptualise the sequential control processes involved in the equiprobable 
task has been proposed (Barry \& De Blasio, 2013), based on the patterning of ERP components identified in young adults using Principal Components Analysis (PCA). This Processing Schema is unique in the literature in attempting to include all the ERP components observed in approximately the first 800 ms after stimulus presentation, and their associated processes, rather than targeting a limited number of components (e.g., only P3) and/or processes (e.g., only inhibition), and provides a working model of processing throughout the task. It has since been supported, extended and updated in a series of programmatic studies across the lifespan (Barry \& De Blasio, 2013, 2015; Barry, De Blasio, \& Borchard, 2014; Barry, De Blasio, \& Cave, 2014, 2016; Barry, De Blasio, Fogarty, \& Karamacoska, 2016). The most recent updates were in young adults (Fogarty et al., 2018), and in children (Barry et al., 2018).

The latest Child Schema is outlined in Fig. 1. In this version of the Schema, initial sensory processing of both stimuli is reflected in the P1, and in N1-3, N1-1, and Processing Negativity, PN (three subcomponents of the N1; Näätänen \& Picton, 1987). P1 and N1-3 are not always extracted by PCA, and these and other non-robust components are indicated in paler font in the model. Component headmaps are shown only for those child components extracted and assessed in Barry et al. (2018). Categorization of the stimulus as Go or NoGo occurs during the latter stages of that sensory processing, and leads to two separate processing streams. Go processing, involving response preparation and execution, is apparent in a vertex P2 (common in young adults, although rarely seen as a separate component in children), the vertex N2c, centroparietal P3b, centroparietal positive Slow Wave (SW), and a frontoparietal Late Negativity (LN). The NoGo processing stream has been characterised in children by a large N2b, a frontal N2c (now labelled as fN2c), a frontocentral P3a, a frontal Negative Slow Wave (NegSW), and a centroparietal Late Positivity (LP).

\section{Figure 1 about here}

Control processes in the Processing Schema have been explored previously by linking variation in a component with variation in behavioural outcomes. For example, larger NoGo N2b amplitudes have been linked to fewer commission errors, suggesting that N2b is active in inhibitory processing, optimising NoGo performance in adults (Fogarty et al., 2018) and in children (Barry \& 
De Blasio, 2015; Barry et al., 2018). Similarly, in the Go processing stream, N2c and P3b are considered to be markers of active response processing (Fogarty et al., 2018; Hillyard, Squires, Bauer, \& Lindsay, 1971; Karamacoska, Barry, \& Steiner, 2017; Nieuwenhuis et al., 2003; Pritchard, Shappell, \& Brandt, 1991; Ritter, Simson, Vaughan, \& Friedman, 1979).

In the present study, rather than linking components to behavioural outcomes, we instead explored the influence of caffeine on the Go/NoGo ERPs in children, seeking to clarify their control processes in the context of the Processing Schema. It has previously been reported that caffeine produces an increase in skin conductance level (SCL) and a decrease in EEG alpha power, markers of arousal increase, in both adults (Barry, Clarke, Johnstone, \& Rushby, 2008; Barry et al., 2005; Bruce, Scott, Lader, \& Marks, 1986; Dimpfel, Schober, \& Spüler, 1993; Etevenon et al., 1986; Flaten \& Blumenthal, 1999; Gilbert, Dibb, Plath, \& Hiyane, 2000; Kaplan et al.,1997; Kenemans \& Lorist, 1995; Newman, Stein, Trettau, Coppola, \& Uhde,1992; Quinlan et al., 2000; Zahn \& Rapoport, 1987) and children (Barry et al., 2009). Previous work within the arousal/activation framework of Pribram and McGuinness (1975) has associated state arousal effects with physiological response amplification (e.g., Barry, Kirkaikul, \& Hodder, 2000; Barry \& Sokolov, 1993; VaezMousavi, Barry, Rushby, \& Clarke, 2007; De Blasio \& Barry, 2013; De Blasio, Barry, \& Steiner, 2013; Steiner \& Barry, 2014). Thus we hypothesised that active control processes, and their ERP component markers, would be differentially enhanced by caffeine.

Despite caffeine being the world's most-commonly consumed stimulant (in soft drinks and coffee; Barone \& Roberts, 1996), there have been relatively few systematic caffeine/ERP studies, and there is a dearth of coherent findings. For example, Lorist, Snel, and Kok (1994) found increased P2 and P3 amplitudes in a visual selective attention task, but Kenemans and Lorist (1995) found little effect on these components in a similar study. In a study of caffeine effects on adult ERPs in this equiprobable Go/NoGo paradigm, Barry et al. (2007) pointed to several reasons for the variability of findings between studies. These included intersubject variability in terms of habitual caffeine ingestion and smoking/nicotine history, acute dose level, time from ingestion to testing, prior abstinence period (important in relation to both wash-out and withdrawal), expectancy effects in 
participants and experimenters, and paradigm differences. Barry et al. (2007) attempted to optimise control of such variables using peak-picked ERP data from a randomised double-blind placebocontrolled repeated-measures cross-over study. It was found that $250 \mathrm{mg}$ of caffeine (cf. placebo) reduced reaction time (RT), but had no effects on omission or commission errors. There were also focal increases in the amplitudes of Go P1, P2, and P3b, but no impact on Go N1 or N2. Caffeine had no effect on NoGo component amplitudes, and no latency effects on Go or NoGo components. That is, caffeine's arousal effects appeared to be confined to the active Go processing and its ERP components. This is compatible with the conclusion of Tieges, Snel, Kok, and Ridderinkhof (2009), based on effects in a range of inhibitory tasks, that caffeine "has little effect on... inhibitory control" (P. 325).

Our temporal PCA study of caffeine effects in the Go/NoGo ERPs of another adult group (Barry, De Blasio, \& Cave, 2014) followed the methodology of our first Processing Schema study (Barry \& De Blasio, 2013), and applied a combined temporal PCA to the Go and NoGo ERPs obtained under caffeine and placebo conditions using the controlled design of Barry et al. (2007). That study reported no main effects of caffeine in either the Go or NoGo components. However, topographic effects of caffeine on the components differed, with some effects in Go PN, P2, and P3b, and in NoGo N1-1, P3a, and SW. These were interpreted as confirming caffeine's contribution to differential Go/NoGo processing. However, our subsequent work on PCA misallocation of variance (Barry, De Blasio, Fogarty, \& Karamacoska, 2016) suggests that those 2014 caffeine results are not optimal, as a combined PCA across Go and NoGo ERPs from both caffeine and placebo conditions, as used there, is likely to smear both the Go vs. NoGo components, and the different caffeine and placebo effects, towards their mean - resulting in misallocation of variance between the four conditions.

This study, aiming to advance the Processing Schema in children, used the controlled design of Barry et al. (2007) with an acute caffeine dose of $80 \mathrm{mg}$, previously confirmed to generate arousal effects in children (Barry et al., 2009), to explore arousal effects in the Go/NoGo paradigm. The timing of data collection was based on our finding that significant arousal effects in adults emerged 
some 20-30 min after caffeine ingestion, and dominated over the next 25-30 min (Barry et al., 2008). Further, in light of our recent work on misallocation of variance in combined (across condition) PCAs (Barry, De Blasio, Fogarty, \& Karamacoska, 2016), we used the optimal procedure of separate temporal PCAs for each combination of conditions: Go/Caffeine, Go/Placebo, NoGo/Caffeine, and NoGo/Placebo. Our focal hypothesis was that the components conceptually associated with the stimulus-specific Go/NoGo processing streams in the Schema (components with bolded red or green labels in Fig. 1) would be enhanced by caffeine. In addition, any caffeine enhancement of currentlyundifferentiated components early in the processing stream (such as P1, N1-1, PN) would provide new insights, such as signalling either the importance of a common processing stage (i.e., if the enhancement is across Go/NoGo), or the differential involvement of a component/process in the Go or NoGo processing stream (i.e., if the enhancement is stimulus-specific).

\section{Methods}

\subsection{Subjects}

Twenty-four children (12 females) were recruited from the local area via advertisements. Their mean age was 10.6 years (SD 1.5, range 8-12), and 18 subjects were right handed (handedness balanced across gender). Participation was restricted to light to moderate caffeine users, those who regularly consumed 1-2 cans of caffeinated cola equivalents weekly, without reporting any adverse effects of caffeine. They were required to abstain from caffeine and other psychoactive substances for at least $4 \mathrm{~h}$ prior to each testing session. Children were screened for neurological disorders, head injuries, learning disabilities and psychiatric conditions. Children with IQ $<85$, outside the normal range on the South Australian Spelling Test and Neale Analysis of Reading, and above a T-score of 65 on any measure of the CPRS-48 Conners rating scale, were excluded. The child's participation was voluntary and written informed consent from the parent/guardian was obtained in line with a protocol approved by the joint University of Wollongong/South East Sydney and Illawarra Area Health Service Human Research Ethics Committee, in accordance with the Declaration of Helsinki. 
Upon completion of the study, children received a certificate, and their parents were recompensed for travel expenses.

\subsection{Physiological recording}

EEG was recorded from 19 sites, using an electrode cap with tin electrodes, referenced to linked ears. Electrode placement was in accord with the international 10-20 system. Vertical and horizontal electro-oculograms (EOGs) were recorded from electrodes above and below the left eye, and beyond the outer canthi of the eyes, respectively. The participant was grounded by a cap electrode at AFz. EEG gain was $\times 20,000$, EOG gain $\times 5,000$, and the data from 0.03 to $35 \mathrm{~Hz}$ were sampled by a 16 bit A/D system (AMLAB II) at $512 \mathrm{~Hz}$ and recorded for off-line analysis.

\subsection{Task and procedure}

The task was a simple unwarned equiprobable auditory Go/NoGo task. Participants received four blocks of 150 tones of 50 ms duration, with $5 \mathrm{~ms}$ rise/fall times, presented via headphones at 60 $\mathrm{dB}$ sound pressure level (SPL) with a fixed stimulus onset asynchrony (SOA) of 1,100 ms. Half the tones were 1,000 Hz and half were 1,500 Hz, presented in random order. Participants were required to button-press to one of the tones, with the target frequency, which differed within subject between sessions, balanced between subjects.

When participants arrived at the laboratory the study was described to the child and parent, and if the child agreed to participate, parents read an information sheet, signed a consent form and completed a screening questionnaire. Children were asked to swallow (with water) one of two identical gelatine capsules, containing either $80 \mathrm{mg}$ caffeine or placebo, in a pre-determined randomised order. Both participants and experimenters were blind to the contents of the capsules. Subjects were then fitted with the physiological measurement equipment, and seated in an airconditioned sound attenuated recording booth.

Recording began approximately 30 min after capsule ingestion. The testing session included the four active Go/NoGo blocks lasting approximately 3 min each, and a number of other tasks not 
reported here. These segments were separated by brief rest periods. Subjects returned for a second testing session at the same time one week later, when the same procedure was followed and the alternate capsule was administered. On average, the Go/NoGo task began 38.1 min (SD $4.1 \mathrm{~min}$ ) after capsule ingestion; this period did not differ between the conditions.

\subsection{Go/NoGo Behavioural Measures}

Commission errors to NoGo stimuli, and response omissions (no response to Go stimuli within the SOA), were computed within subject. RT mean $(M)$ and $S D$ for responses within the SOA were calculated, and responses outside the within-subject $M \pm 1.5 S D$ RT window were identified as Fast or Delayed RT errors.

\subsection{ERP quantification}

The continuous EEG waveforms were lowpass filtered to $25 \mathrm{~Hz}$ (zero phase shift, 24 dB/Octave, FIR), epoched (-100 to $+800 \mathrm{~ms}$ ), and baselined (-100 to $0 \mathrm{~ms}$ ) offline using Neuroscan software (Compumedics, Version 4.5.1). Single trials containing muscular or other artefact exceeding $\pm 100 \mu \mathrm{V}$ at any EOG or scalp electrode, or incorrect responses including commission errors to NoGo stimuli, response omissions to Go stimuli (within the SOA), and responses outside the within-subject $M \pm 1.5 S D$ RT window, were automatically detected and excluded from further analysis. The remaining trials were averaged within each subject, for each block of each drug (caffeine/placebo) and stimulus (Go/NoGo) condition, forming 16 average ERPs at the 19 electrodes sites for each subject.

Temporal PCA was carried out in MATLAB using Kayser and Tenke’s (2003) erpPCA functions (http://psychophysiology.cpmc.columbia.edu/software/), with a heuristic modification from Dien (2010) as discussed in Barry, De Blasio, Fogarty, and Karamacoska (2016). This was used rather than a sequential temporospatial PCA in order to maximise the variance associated with each analysed component. The input data consisted of the four sets of average ERPs defined above (Go/Caffeine, Go/Placebo, NoGo/Caffeine, NoGo/Placebo), each containing 1,824 cases (4 blocks $\times$ 
19 EEG electrode sites $\times 24$ subjects), each case being an ERP containing 900 ms of data. For our data recorded at $512 \mathrm{~Hz}, 900$ ms contains 461 data points, the variables for the PCA, leading to a case/variable ratio $\sim 4.0$. These datasets were subject to four separate temporal PCAs using the covariance matrix with Kaiser normalisation, followed by an unrestricted Varimax rotation (i.e., all 461 factors were VARIMAX-rotated), following Kayser and Tenke (2003). Starting with those that accounted for the most variance in the data, components were identified as ERPs based on their latency, topography, consistency with the raw ERP waveform, similarity to the published data in Fig. 1, and known stimulus-specific properties. Only components carrying more than $2 \%$ of the variance were examined further.

\subsection{Statistical analysis}

Behavioural data were analysed using a correlated-samples t-test (Caffeine vs. Placebo), and as caffeine was expected to improve performance, one-way probabilities are reported. The number of accepted trials in the ERPs was checked with a repeated-measures MANOVA (via syntax in IBM SPSS Statistics version 21), with Stimulus (Go, NoGo) and Condition (Caffeine, Placebo) as withinsubjects factors. The two sets of unscaled factor loadings (Caffeine, Placebo) for each processing stream (Go, NoGo) were compared using the Congruence Coefficient ( $r_{c}$; Tucker, 1951) to illuminate latency and amplitude similarities and differences. This is evaluated using a rule of thumb: equality is indicated by $r_{c} \geq 0.95$, and fair similarity by $.85 \leq r_{c} \leq .94$ (Lorenzo-Seva \& ten Berge, 2006). Component headmaps represent the amplitude at each scalp site, and the topographies of Caffeine/Placebo components were compared by correlating corresponding values from each of the 19 pairs of sites.

Caffeine effects on the NoGo and Go components were analysed separately. Component amplitudes were analysed using repeated-measures MANOVAs over the nine inner sites (F3, Fz, F4, C3, Cz, C4, P3, Pz, P4), with factors of Condition (Caffeine vs. Placebo) plus topographic factors of Sagittal (frontal [F3, Fz, F4], central [C3, Cz, C4], and parietal [P3, Pz, P4]) and Lateral (left [F3, C3, P3], midline [Fz, Cz, Pz], right [F4, C4, P4]) dimensions. Contrasts for the sagittal factor compared frontal $(\mathrm{F})$ versus posterior $(\mathrm{P})$, and central $(\mathrm{C})$ versus the mean of frontal and posterior regions $(\mathrm{F} / \mathrm{P})$. 
Contrasts for the lateral factor compared left (L) versus right (R) hemispheres, and midline (M) versus the mean of the hemispheres (L/R). For the temporal PN, F3/4, C3/4, P3/4 were replaced by F7/8, T7/8, P7/8, respectively. As the contrasts were all planned and did not exceed the degrees of freedom for effect, no Bonferroni-type adjustment of $\alpha$ levels was required (Tabachnick \& Fiddell, 2013). All contrasts reported had $d f=(1,23)$.

For each component, significant topographic contrasts across conditions were taken as the best estimate defining the component. Significant interactions of these defining contrasts with Condition were taken to indicate Caffeine effects on the component. For example, if a component showed a significant parietal effect across conditions (i.e., $\mathrm{F}<\mathrm{P}$ ), this was taken as a defining characteristic of that component. If that parietal topography then interacted with Condition, this was considered to reflect a Caffeine effect on the component, while interactions of Condition with other (non-defining) topographic contrasts were considered random topographic effects.

\section{Results}

\subsection{Behavioural data}

As shown in Table 1, caffeine was associated with significant reductions in Go omission errors and mean Go RT. Fast and delayed Go RT errors, NoGo commission errors, and Go RT variability each failed to show any significant effect of caffeine.

\section{Table 1 about here}

\subsection{ERPs}

Across the four blocks, on average there were $173.9(S D=41.0)$ accepted trials in each mean Go ERP, and $183.1(S D=46.0)$ in each mean NoGo ERP, with no participant contributing less than 89 trials. There were more accepted trials in caffeine $(M=187.7, S D=42.3)$ than placebo $(M=$ 169.4, $S D=43.3 ; F=5.39, p=.030, \eta_{\mathrm{p}}^{2}=.19$ ), but these numbers did not differ with stimulus condition. Panel A of Fig. 2 shows the midline mean ERPs for Go and NoGo stimuli (across caffeine and placebo). There was a clear frontal P1 around 70 ms, and a frontal N1 around $100 \mathrm{~ms}$, followed 
by a very large frontal N2 around 220 ms. This was followed by marked P3s near 330 ms, with apparent topographic differences between the small NoGo (central) and later large Go (parietal) responses. P3 was followed by a classic frontal-negative/parietal-positive SW, and NoGo LP. Caffeine appeared to have both early and late effects on the ERPs to Go stimuli (see Fig. 2 Panel B), and somewhat smaller and different effects on NoGo responses (see Fig. 2 Panel C).

\section{Figure 2 about here}

\subsection{Go PCA components}

The first seven factors in variance order from each Go PCA (Caffeine, Placebo) accounted for individual variances $>2 \%$; these included six factors that appeared to correspond. Component 5 in placebo and component 6 in caffeine were discarded, despite each carrying more than $2 \%$ variance, as their matching components (found beyond the first seven factors) did not meet this minimum variance criterion. The six corresponding components accounted for $85.3 \%$ of the total variance in Caffeine, and $82.8 \%$ in Placebo. The sums of these components are displayed as virtual ERPs in Fig. 2 (panels D and E), corresponding to the adjacent raw Go ERPs. The PCAs can be seen to have produced virtual Go ERPs that generally match the raw ERPs (compare right panels with left). Correlations between the reconstituted (Panel E) and raw (Panel B) Go waveforms at each of the midline sites ranged between .92 and .99 for Caffeine and .93 and .98 for Placebo; all were highly significant $(p<.001)$, confirming their good approximation to the raw data.

Fig. 3 displays topographic headmaps of the peak component amplitudes for the six identified Go components in each condition. The factor number, peak latency, and unique variance associated with each component are also presented with the headmaps. Component labels reflect their temporal sequence, latency, similarity to the components identified in the raw ERPs, and the previous separate PCA outcomes found for children in this paradigm (Barry et al., 2018), but with the addition of an initial P1. P1 was followed by N1-1 and the PN (dominant in temporal regions). These were followed, in latency order, by components identifiable as N2c, P3b, and a LN. For each component, the Congruence Coefficient $r_{c}$, and the topographic correlation $r(17)$ between the 19 pairs of electrodes, are listed between the two sets of headmaps. The Congruence coefficients indicated that 
Go PN and N2c timings and amplitudes were similar in Caffeine and Placebo, while all other components were identical. All topographic correlations between the Caffeine and Placebo Go components were significant, $r(17) \geq .77, p<.001$, indicating highly-similar components in each condition.

\section{Figure 3 about here}

\subsubsection{Go component topographies}

The MANOVA indicated that P1 was strongly frontal $\left(\mathrm{F}>\mathrm{P}: \mathrm{F}=33.36, p<.001, \eta_{\mathrm{P}}{ }^{2}=.59\right.$; $\left.\mathrm{C}<\mathrm{F} / \mathrm{P}: F=5.04, p=.035, \eta_{\mathrm{P}}^{2}=.18\right)$, and somewhat reduced centrally in the hemispheres $(\mathrm{C}<\mathrm{F} / \mathrm{P}$ $\left.\times \mathrm{M}<\mathrm{L} / \mathrm{R}: F=3.66, p=.068, \eta_{\mathrm{P}}^{2}=.14\right)$ and significantly so in the central right $(\mathrm{C}<\mathrm{F} / \mathrm{P} \times \mathrm{L}<\mathrm{R}: F$ $\left.=5.00, p=.035, \eta_{\mathrm{P}}^{2}=.18\right)$. These results and other Go component MANOVA results are shown in Table 2. Note the shading there indicating a directional reversal in the corresponding P1 effect (i.e., the central reduction, not increase), and the statistical equivalence of the effect with two directional reversals (i.e., the central hemispheric reduction). In order to save space, subsequent results here omit statistics from the text as they are reported in Table 2. N1-1 was somewhat larger in the frontal (cf. parietal) region, and this frontal enhancement was significantly larger in the hemispheres compared with the midline, and was reduced centrally compared with frontal and parietal regions, particularly in the left compared with the right hemisphere. PN was more negative frontally, and in the hemispheres, particularly the right hemisphere; frontally, PN was larger on the right, and centrally, it was larger in the hemispheres, reflecting its defining temporal topography. N2c was frontocentral and midline dominant; the frontal dominance was somewhat enhanced in the midline, and the central dominance was significantly enhanced in the midline. P3b was centroparietal, and the parietal enhancement was largest in the midline. The LN was reduced centrally, and enhanced in the midline and left hemisphere; the LN midline enhancement was frontocentral, and the left hemisphere enhancement was central. These significant topographic effects across Condition are taken as the defining characteristics of the Go components.

\section{Table 2 about here}

\subsubsection{Go component caffeine effects}


As shown in the bottom part of Table 2, Caffeine was associated in the Go P1 with a slight increase in positivity that was significantly smaller at the vertex, and there was some central reduction in N1-1. These effects on the non-defining topographic contrasts can be seen in a comparison of the two rows of headmaps in Fig. 3. With PN, Caffeine reduced negativity frontally, in the midline and right hemisphere, but enhanced the defining relative central hemispheric negativity. N2c was globally enhanced by Caffeine, particularly in frontal and hemispheric regions. P3b was also globally enhanced, and the LN showed some left central increase with Caffeine.

\subsection{NoGo PCA outcomes}

Of the first nine factors in variance order from each NoGo PCA, eight appeared to correspond. Component 7 in placebo and component 7 in caffeine each carried more than $2 \%$ variance, but neither had a matching component in the other condition. Individually the corresponding components accounted for $>2 \%$ variance, and together they accounted for $85.6 \%$ of the total variance in Caffeine, and $82.1 \%$ in Placebo. The sums of these components are displayed as virtual ERPs in Fig. 2 (panels D and F), corresponding to the adjacent raw NoGo ERPs. The PCAs appear to have produced virtual NoGo ERPs that match the raw ERPs (compare right panels with left). Correlations between the reconstituted (Panel F) and raw (Panel C) mean NoGo waveforms at each of the midline sites ranged between .96 and .98 for caffeine and between .95 and .99 for placebo; all were highly significant $(p<.001)$, confirming their good approximation to the raw data.

Fig. 4 displays topographic headmaps of peak component amplitudes and component information for the eight identified NoGo components in each condition. The component factor number, peak latency, and percent variance accounted for, are shown for each headmap. Components were identified in terms of their timing, sequence, and similarity to the raw ERP components and those previously identified. P1 was again followed by N1-1 and PN. These were followed, in latency order, by components identifiable from the revised Child Schema as N2b, fN2c, P3a, NegSW, and LP. The Congruence coefficients in Fig. 4 indicated that NoGo PN was similar 
between Caffeine and Placebo, while all other components showed equivalence between conditions, except for N2b, which differed largely because of its magnitude difference. All topographic correlations between the Caffeine and Placebo NoGo components were significant, $r(17) \geq .71, p<$ .001 , indicating that there were highly-similar components in both conditions.

\section{Figure 4 about here}

\subsubsection{NoGo component topographies}

As shown in Table 3, MANOVAs indicated that NoGo P1 was frontal, larger in the midline, and reduced centrally on the right and in the midline. N1-1 was strongly frontal and dominant in the midline; central negativity was larger on the right and largest at the vertex. PN was larger frontally, particularly in the midline, and in the hemispheres, particularly the right hemisphere; centrally, PN was larger in the hemispheres, confirming its defining temporal topography. The NoGo N2b was frontocentral and dominant on the right, with the frontal dominance enhanced in the midline. The NoGo fN2c was frontal, with some central right enhancement. P3a was frontal and midline, and there was a frontocentral enhancement in the midline. NegSW was strongly frontal, somewhat larger on the left, and largest in the frontal midline. The LP was centroparietal, and reduced in the midline; the midline reduction was frontocentral, and there was some frontal left reduction. Significant topographic effects across Condition are taken as the defining characteristics of the NoGo components.

\section{Table 3 about here}

\subsubsection{NoGo component caffeine effects}

In the NoGo components, Caffeine was associated in P1 with a relative reduction in the left hemisphere and central right region; see the bottom part of Table 3 and compare the two rows of headmaps in Fig. 4. In N1-1, Caffeine produced an increase centrally, in the midline, and at the vertex; enhancing most of its defining topography. With PN, Caffeine reduced negativity in the right hemisphere, and frontally in the midline; overall, the component became less negative in Caffeine. N2b was globally enhanced by Caffeine, particularly in frontal and hemispheric regions, but least at the vertex. The NoGo fN2c component was significantly reduced globally by Caffeine, particularly 
frontocentrally, in the midline, and frontocentrally in the midline. NoGo P3a was reduced by Caffeine centrally, particularly in the left hemisphere. With Caffeine, NegSW showed some frontal increase, and the LP showed some hemispheric increase; both these effects are in aspects of the defining topographies.

\section{Discussion}

The PCA components obtained separately for Go and NoGo under caffeine and placebo broadly match those recently used to generate our updated Processing Schema for children in this equiprobable paradigm (Barry et al., 2018; see Fig. 1). In addition, a consistent but small P1 was obtained here. This component is not always reported, but is often seen with $<2 \%$ of the variance, our usual cut-off for detailed consideration. The mean topographic results obtained here, presented in the upper halves of Tables 2 and 3, appear to be a general match to those obtained previously, suggesting that the present child sample is typical/representative of this population.

\subsection{Caffeine effects}

In this double-blind placebo-controlled cross-over study, caffeine was associated with a reduction in Go omissions. RT was reduced by caffeine compared with placebo, but RT variability did not change with caffeine. That is, caffeine improved Go performance significantly in accuracy and speed, but had no effect on response consistency. There was no reduction in NoGo commission errors, but this might reflect a floor effect, as the NoGo task was performed quite efficiently $(<5 \%$ errors on average).

Of most interest here is the effect of caffeine on the ERP components. Of the Go components, P1 and N1-1 both had localised changes that did not reflect the overall topography. The frontal and midline negativity of PN was reduced by caffeine, but more importantly, the defining temporal (cf. vertex) negativity was enhanced. N2c and P3b were both globally enhanced by caffeine 
(see Fig. 3), but LN showed no significant effects.

In the NoGo components, P1 again had localised changes that did not reflect the overall defining topography. NoGo N1-1 was enhanced in most of its defining regions, particularly in the midline and vertex regions. PN became globally less negative in caffeine, although the defining temporal negativity was unaffected. Caffeine generally enhanced N2b as predicted, and reduced fN2c. P3a was topographically reduced by caffeine, in regions beyond its defining topography, suggesting that it is not engaged with N2b in conflict monitoring/premotor inhibitory processing; perhaps it may be involved in motor inhibition (see Pires et al., 2014). The NegSW and LP showed non-significant effects in aspects of their defining topography.

\subsection{Effects on schema stages}

Overall, our major hypotheses were supported. We had proposed that active control-related components of our Schema's segregation into separate Go and NoGo processing streams should be differentially enhanced by caffeine. For ease of understanding, we address these findings in terms of the stages in the Child Processing Schema shown in Fig. 1.

\subsubsection{Sensory processing and Go/NoGo categorization}

The lack of substantial caffeine effects in P1 is compatible with its Schema placement in a pre-categorization period of processing bridging from early sensory processing, and common to all stimuli.

The defining topographic features of the N1-1 were mostly enhanced by caffeine in NoGo, but not Go. In contrast, the defining aspects of the Go PN were significantly enhanced by caffeine, while caffeine had no effect in the case of the NoGo PN. These outcomes are compatible with expectations of components marking Go/NoGo categorization stages - the same components occur in response to both Go and NoGo, but are differentially enhanced by caffeine when active categorization of the NoGo (N1-1) or Go (PN) stimulus is emerging. This interpretation of the NoGo N1 is compatible with the view of it as marking the NoGo decision (Filipović, Jahanshahi, \& 
Rothwell, 2000; Kirmizi-Alsan et al., 2006).

\subsubsection{Go-specific processing}

As described in the Introduction, in the Go processing stream, N2c and P3b are considered to be markers of active response processing. Each of these components was significantly enhanced by caffeine, strongly supporting their placement and functioning in the Go processing stream.

\subsubsection{NoGo-specific processing}

In the NoGo stream, N2b has been recognised as the critical marker of active inhibitory control, being related to reduced numbers of commission errors. This component was significantly enhanced by caffeine, strongly supporting its placement and function in the NoGo processing stream.

Unexpected results for three other NoGo components are of interest. The NoGo fN2c, which occurs in the same timeframe as the Go N2c but with a different topography (and hence is likely to be a different component), was the only component with significantly decreased global amplitude with caffeine. We had not reported this component before our recent upgrade of the Child Schema with improved PCA methodology (Barry et al., 2018), and are yet to determine its function in this paradigm. Speculatively, the present caffeine effect suggests that fN2c may be a marker of postinhibition evaluation: caffeine increases N2b (marking greater inhibition), and perhaps fN2c reduces because there is less need for evaluation of the success of inhibition. The next component showing an unexpected effect was NoGo NegSW. This component has been previously found to be larger with greater commission error rates, and its occurrence after the mean Go RT led to its identification as a late NoGo evaluative process (Barry et al., 2018), perhaps associated with the Correct Response Negativity/ERN (e.g., Vidal, Hasbroucq, Grapperon, \& Bonnet, 2000). The topography of the NegSW is strongly frontal, and here caffeine was found to enhance that frontal activity, in line with our prediction. However, this failed to reach statistical significance; but note that if a one-way test was used rather than the two-way F-test, it would have shown a significant amplitude increase with caffeine. Similarly, the hemispheric LP, posited to mark the early cessation of processing in the 
NoGo stream (in the absence of a response requirement; Barry \& De Blasio, 2013), was nonsignificantly enhanced hemispherically by caffeine; again, this would have been significant if a oneway test had been used.

\subsection{Schema modifications}

In summary, we found significant enhancements of Go PN, N2c, and P3b, and NoGo N1-1 and N2b with caffeine, as well as non-significant but supportive enhancements in NoGo NegSW and LP. There was also a novel finding of a reduction in NoGo fN2c amplitude with caffeine that could provide insights into its functional role in this paradigm. In the light of these findings, some minor modifications of the Child Processing Schema are warranted. Fig. 5 incorporates these updates (cf. the schema in Fig. 1). The new bolding of the P1 and NoGo fN2c components indicates our greater confidence in their stability, derived from their present confirmation in a new child sample with separate condition PCAs, and from ERPs collected under placebo and caffeine.

\section{Figure 5 about here}

In the Child Processing Schema, P1 is now confirmed as marking early sensory processing that does not distinguish between Go and NoGo. Caffeine enhanced the defining midline and vertex topography of the NoGo N1-1 component, suggesting that identification and categorization of the NoGo stimulus, and its reflection in this component, has begun, and that this active processing has been amplified by caffeine. In contrast, Go PN had its defining temporal topography enhanced by caffeine, suggesting that PN marks the categorization phase for the Go stimulus at the end of sensory processing. Accordingly, these early Go/NoGo updates are indicated in the model by the red/green colour labels for NoGo N1-1 and Go PN (respectively) in these processing stages, while maintaining the same labels in black for the unaffected condition. The "categorization" stage is now terminated directly after PN; subsequent processing is marked by different Go and NoGo components. In the post-categorization Go processing stream, caffeine amplified N2c and P3b as expected, confirming their active processing. Although all nine core LN sites were more negative in caffeine than placebo, this failed to approach statistical significance, suggesting that its proposed function - a late post- 
response error evaluation (Barry et al., 2018) - was not affected by arousal. Hence, this novel child component needs further research in future studies.

In the post-categorization NoGo stream, caffeine enhanced N2b, the primary indicator of the control process of response inhibition in this paradigm (Barry et al., 2018; Fogarty et al., 2018), as predicted. We have not resolved the function of the child P3a in previous studies (e.g., Barry et al., 2018), and the present study has yielded no new insights. There were no significant caffeine effects in either the NegSW or LP, respectively postulated to reflect a late error-evaluation process and general reduction in cortical activation after the earlier trial completion in NoGo (cf. Go) processing (Barry et al., 2018). However, the implications of the non-significant effects of caffeine support their active roles within the Child Schema. In addition, one other finding is of some interest - the reduced NoGo fN2c in caffeine compared to placebo. When first reported in our previous child study (as NoGo N2c; Barry et al., 2018), it was regarded as some sort of "place holder" in the NoGo processing stream in this population, corresponding to the timing of the Go N2c rather than its function. Perhaps this component reflects the child's uncertainty or conflict regarding Go/NoGo processing (Botvinick et al., 2001; Nieuwenhuis et al., 2003). Alternatively, it might reflect some activation of the Go response preparation carried through in the Go stream with the N2c/P3b processing, but not completed in successful NoGo trials. Its reduction in caffeine could then reflect a second active inhibition process in children. This possibility needs further investigation, but the confirmation of this component here warrants its inclusion in bold type in the revised Child Schema shown in Fig. 5.

\subsection{Strengths and limitations}

The major strength of this study lies not in the study of caffeine per se, but in the novel use of caffeine as a specific amplifying factor to test the active-processing aspects of the separate Go and NoGo streams of the Child Processing Schema. The Schema itself is also novel - it is the only coherent conceptualisation of the processing chain encompassing all ERP components found in the first 800 ms poststimulus in this paradigm. In turn, this paradigm sits at the midpoint of all simple 
two-choice active-response paradigms, and has potential to bring new insights into this major class of cognitive processing designs.

Further novelty arises in this study with the application of separate PCAs carried out on the Go and NoGo datasets rather than the traditional combined PCA on the joint Go/NoGo data. This avoids the misallocation of variance between the Go and NoGo components, which tends to blend aspects of the separate Go vs. NoGo components, obscuring their real differences (Barry, De Blasio, Fogarty, \& Karamacoska, 2016). This blending would have been further exacerbated if PCAs had been based on data including both Caffeine and Placebo responses. This significant improvement in our novel PCA approach rules out meaningful comparisons with previous PCA studies in the child/caffeine area, and sets the benchmark for future research.

Although our gender-matched sample of children tested in a double-blind repeated-measures cross-over design, with $N=24$, is quite substantial in the context of the vast bulk of the child ERP literature, we would have more confidence in the reliability of our results if the sample was larger. This issue should be considered in future work.

\subsection{Conclusions and future directions}

This study utilised the stimulant properties of caffeine to increase the arousal state of children undertaking the equiprobable auditory Go/NoGo task. We hypothesised that this would enhance ERP components reflecting active control processing in the task, as modelled in the Processing Schema for children first proposed by Barry and De Blasio (2015), and recently updated by Barry et al. (2018). This general hypothesis was supported, and additional caffeine/placebo differences were used to further extend the Child Schema. Caffeine thus appears to be a useful tool for future studies of control processes in a range of paradigms and across the lifespan, and further studies of the Processing Schema appear promising.

The equiprobable auditory Go/NoGo task used to generate the Processing Schema, and employed here, is at the probability midpoint between traditional high target probability Go/NoGo (target $p>.5$ ) and traditional low target probability Oddball tasks (target $p<.5$ ), and thus may be 
regarded as a proxy for these (and indeed, all) two-choice decision tasks. Future studies are necessary to illuminate the applicability of the Schema across this range, but it should serve as a beginning point for a detailed understanding of the sequential processes involved, and their ERP component markers. We have begun such extensions in relation to the classic Oddball task in adults (Fogarty, Barry, \& Steiner, in press), and extensions to the rare NoGo variants of the Go/NoGo task are in progress. Improved understanding of the control processes and their indices in these tasks, and their trajectory across the lifespan, might provide important markers for the detection, treatment, and/or monitoring of control related dysfunction in clinical and subclinical populations.

\section{Acknowledgments}

This research did not receive any specific grant from funding agencies in the public, commercial, or not-for-profit sectors. JSF was supported by an Australian Government Research Training Program Scholarship. 


\section{References}

Barone, J. J., \& Roberts, H. R. (1996). Caffeine consumption. Food and Chemical Toxicology, 34, 119-129. https://doi.org/10.1016/0278-6915(95)00093-3

Barry, R. J., Clarke, A. R., Johnstone, S. J., Brown, C. R., Bruggemann, J. M., \& van Rijbroek, I. (2009). Caffeine effects on resting-state arousal in children. International Journal of Psychophysiology, 73, 355-361. https://doi.org/10.1016/j.ijpsycho.2009.05.012

Barry, R. J., Clarke, A. R., Johnstone, S. J., \& Rushby, J. A. (2008). Timing of caffeine’s impact on autonomic and central nervous system measures: Clarification of arousal effects. Biological Psychology, 77, 304-316. https://doi.org/10.1016/j.biopsycho.2007.11.002

Barry, R. J., \& De Blasio, F. M. (2013). Sequential processing in the equiprobable auditory Go/NoGo task: A temporal PCA study. International Journal of Psychophysiology, 89, 123-127. https://doi.org/10.1016/j.clinph.2014.02.018

Barry, R. J., \& De Blasio, F. M. (2015). Performance and ERP components in the equiprobable go/no-go task: Inhibition in children. Psychophysiology, 52, 1228-1237. https://doi.org/10.1111/psyp.12447

Barry, R. J., De Blasio, F. M., \& Borchard, J. P. (2014). Sequential processing in the equiprobable auditory Go/NoGo task: children vs. adults. Clinical Neurophysiology, 125, 1995-2006. https://doi.org/10.1016/j.clinph.2014.02.018

Barry, R. J., De Blasio, F. M., \& Cave, A. E. (2014). Caffeine Effects on ERP Components and Performance in an Equiprobable Auditory Go/NoGo Task. Journal of Caffeine Research, 4, 8392. https://doi.org/10.1089/jcr.2014.0011

Barry, R. J., De Blasio, F. M., \& Cave, A. E. (2016). Sequential processing in younger and older adults in the equiprobable auditory Go/NoGo task. Clinical Neurophysiology, 127, 2273-2285. https://doi.org/10.1016/j.clinph.2016.02.010

Barry, R. J., De Blasio, F. M., \& Fogarty, J. S. (2018). A processing schema for children in the 
auditory equiprobable Go/NoGo task: ERP components and behaviour. International Journal of Psychophysiology, 123, 74-79. https://doi.org/10.1016/j.ijpsycho.2017.10.014

Barry, R. J., De Blasio, F. M., Fogarty, J. S., \& Karamacoska, D. (2016). ERP Go/NoGo condition effects are better detected with separate PCAs. International Journal of Psychophysiology, 106, 50-64. https://doi.org/10.1016/j.ijpsycho.2016.06.003

Barry, R. J., Johnstone, S. J., Clarke, A. R., Rushby, J. A., Brown, C. R., \& McKenzie, D. N. (2007). Caffeine effects on ERPs and performance in an auditory Go/NoGo task. Clinical Neurophysiology, 118, 2692-2699. https://doi.org/10.1016/j.clinph.2007.08.023/

Barry, R. J., Kirkaikul, S., \& Hodder, D. (2000). EEG alpha activity and the ERP to target stimuli in an auditory oddball paradigm. International Journal of Psychophysiology, 39, 39-50. https://doi.org/10.1016/S0167-8760(00)00114-8

Barry, R. J., \& Rushby, J. A. (2006). An orienting reflex perspective on anteriorisation of the P3 of the event-related potential. Experimental Brain Research, 173, 539-545. https://doi.org/10.1007/s00221-006-0590-8

Barry, R. J., Rushby, J. A., Wallace, M. J., Clarke, A. R., Johnstone, S. J., \& Zlojutro, I. (2005). Caffeine effects on resting-state arousal. Clinical Neurophysiology, 116, 2693-2700. https://doi.org/10.1016/j.clinph.2005.08.008

Barry, R. J., \& Sokolov, E. N. (1993). Habituation of phasic and tonic components of the orienting reflex. International Journal of Psychophysiology, 15, 39-42. https://doi.org/10.1016/01678760(93)90093-5

Botvinick, M. M., Braver, T. S., Barch, D. M., Carter, C. S., \& Cohen, J. D. (2001). Conflict monitoring and cognitive control. Psychological Review, 108, 624-652. http://dx.doi.org/10.1037/0033-295X.108.3.624

Bruce, M., Scott, N., Lader, M., \& Marks, V. (1986). The psychopharmacological and electrophysiological effects of single doses of caffeine in healthy human subjects. British Journal of Clinical Pharmacology, 22, 81-87. https://doi.org/10.1111/j.1365- 
De Blasio, F. M., \& Barry, R. J. (2013). Prestimulus alpha and beta determinants of ERP responses in the Go/NoGo task. International Journal of Psychophysiology, 89, 9-17. https://doi.org/10.1016/j.ijpsycho.2013.04.018

De Blasio, F. M., Barry, R. J., \& Steiner, G. Z. (2013). Prestimulus EEG amplitude determinants of ERP responses in a habituation paradigm. International Journal of Psychophysiology, 89, 444450. https://doi.org/10.1016/j.ijpsycho.2013.05.015

Dien, J. (2010). The ERP PCA Toolkit: An open source program for advanced statistical analysis of event-related potential data. Journal of Neuroscience Methods, 187, 138-145. https://doi.org/10.1016/j.jneumeth.2009.12.009

Dimpfel, W., Schober, F., \& Spüler, M. (1993). The influence of caffeine on human EEG under resting condition and during mental loads. The Clinical Investigator, 71, 197-207. https://doi.org/10.1007/BF00180102

Donkers, F. C. L., \& van Boxtel, G. J. M. (2004). The N2 in go/no-go tasks reflects conflict monitoring not response inhibition. Brain and Cognition, 56, 165-176. https://doi.org/10.1016/j.bandc.2004.04.005

Enriquez-Geppert, S., Konrad, C., Pantev, C., \& Huster, R. J. (2010). Conflict and inhibition differentially affect the N200/P300 complex in a combined go/nogo and stop-signal task. NeuroImage, 51, 877-887. https://doi.org/10.1016/j.neuroimage.2010.02.043

Etevenon, P., Péron-Magnan, P., Boulenger, J. P., Tortrat, D., Guillou, S., Toussaint, M., ... \& Zarifian, E. (1986). EEG cartography profile of caffeine in normals. Clinical Neuropharmacology, 9, 538-540.

Falkenstein, M., Hoormann, J., \& Hohnsbein, J. (1999). ERP components in Go/Nogo tasks and their relation to inhibition. Acta Psychologica, 101, 267-291. https://doi.org/10.1016/S00016918(99)00008-6

Filipović, S.R., Jahanshahi, M., \& Rothwell, J.C. (2000). Cortical potentials related to the nogo decision. Experimental Brain Research, 132, 411-415. https://doi.org/10.1007/s00221000349 Flaten, M. A., \& Blumenthal, T. D. (1999). Caffeine-associated stimuli elicit conditioned responses: 
an experimental model of the placebo effect. Psychopharmacology, 145, 105-112. https://doi.org/10.1007/s002130051038

Fogarty, J. S., Barry, R. J., De Blasio, F. M., \& Steiner, G. Z. (2018). ERP components and behavior in the auditory equiprobable go/no-go task: Inhibition in young adults. Psychophysiology, 55, e13065. https://doi.org/10.1111/psyp.13065

Fogarty, J. S., Barry, R. J., \& Steiner, G. Z. (in press). Sequential processing in the classic oddball task: ERP components, probability, and bahaviour. Psychophysiology.

Gilbert, D. G., Dibb, W. D., Plath, L. C., \& Hiyane, S. G. (2000). Effects of nicotine and caffeine, separately and in combination, on EEG topography, mood, heart rate, cortisol, and vigilance. Psychophysiology, 37, 583-595. https://doi.org/10.1111/1469-8986.3750583

Hillyard, S. A., Squires, K. C., Bauer, J. W., \& Lindsay, P. H. (1971). Evoked potential correlates of auditory signal detection. Science, 172, 1357-1360. http://dx.doi.org/10.1126/science.172.3990.1357

Huster, R. J., Enriquez-Geppert, S., Lavallee, C. F., Falkenstein, M., \& Herrmann, C. S. (2013). Electroencephalography of response inhibition tasks: Functional networks and cognitive contributions. International Journal of Psychophysiology, 87, 217-233. https://doi.org/10.1016/j.ijpsycho.2012.08.001

Karamacoska, D., Barry, R. J., \& Steiner, G. Z. (2017). Resting state intrinsic EEG impacts on go stimulus-response processes. Psychophysiology, 54, 894-903. https://doi.org/10.1111/psyp.12851

Kayser, J., \& Tenke, C. E. (2003). Optimizing PCA methodology for ERP component identification and measurement: Theoretical rationale and empirical evaluation. Clinical Neurophysiology, 114, 2307-2325. https://doi.org/10.1016/S1388-2457(03)00241-4

Kenemans, J. L., \& Lorist, M. M. (1995). Caffeine and selective visual processing. Phasrmacology Biochemistry and Behavior, 52, 461-471. https://doi.org/10.1016/0091-3057(95)00159-T

Keplan, G. B., Greenblatt, D. J., Ehrenberg, B. L., Goddard, J. E., Cotreau, M. M., Harmatz, J. S., \& Shader, R. I. (1997). Dose-Dependent Pharmacokinetics and Psychomotor Effects of Caffeine in 
Humans. The Journal of Clinical Pharmacology, 37, 693-703. https://doi.org/10.1002/j.15524604.1997.tb04356.x

Kirmizi-Alsan, E., Bayraktaroglu, Z., Gurvit, H., Keskin, Y. H., Emre, M., \& Demiralp, T. (2006). Comparative analysis of event-related potentials during Go/NoGo and CPT: Decomposition of electrophysiological markers of response inhibition and sustained attention. Brain Research, 1104, 114-128. https://doi.org/10.1016/j.brainres.2006.03.010

Lorenzo-Seva, U., \& ten Berge, J. M. F. (2006). Tucker’s congruence coefficient as a meaningful index of factor similarity. Methodology, 2, 57-64. https://doi.org/10.1027/1614-2241.2.2.57

Lorist, M. M., Snel, J., \& Kok, A. (1994). Influence of caffeine on information processing stages in well rested and fatigued subjects. Psychopharmacology, 113, 411-421. https://doi.org/10.1007/BF02245217

Näätänen, R., \& Picton, T. (1987). The N1 wave of the human electric and magnetic response to sound: A review and an analysis of the component structure. Psychophysiology, 24, 375-425. https://doi.org/10.1111/j.1469-8986.1987.tb00311.x

Newman, F., Stein, M. B., Trettau, J. R., Coppola, R., \& Uhde, T. W. (1992). Quantitative electroencephalographic effects of caffeine in panic disorder. Psychiatry Research: Neuroimaging, 45, 105-113. https://doi.org/10.1016/0925-4927(92)90004-N

Nieuwenhuis, S., Yeung, N., van den Wildenberg, W., \& Ridderinkhof, K. R. (2003). Electrophysiological correlates of anterior cingulate function in a Go/NoGo task: Effects of response conflict and trial-type frequency. Cognitive, Affective, \& Behavioural Neuroscience, 3, 17-26. http://doi.org/10.3758/CABN.3.1.17

Pfefferbaum, A., Ford, J. M., Weller, B. J., \& Kopell, B. S. (1985). ERPs to response production and inhibition. Electroencephalography and Clinical Neurophysiology, 60, 423-434. https://doi.org/10.1016/0013-4694(85)91017-X

Pires, L., Leitão, J., Guerrini, C., \& Simões, M. R. (2014). Event-related potentials in the study of inhibition: Cognitive control, source localization, and age-related modulations. Neuropsychology Review, 24, 461-490. https://doi.org/10.1007/s11065-014-9275-4 
Pribram, K. H., \& McGuinness, D. (1975). Aruosal, activation, and effort in the control of attention. Psychological Review, 82, 116-149. http://dx.doi.org/10.1037/h0076780

Pritchard, W. S., Shappell, S. A., \& Brandt, M. E. (1991). Psychophysiology of N200/N400: A review and classification scheme. In J. R. Jennings, \& P. K. Ackles (Eds.), Advances in psychophysiology: A research annual (Vol. 4, pp. 43-106). London: Jessica Kingsley Publishers Ltd.

Quinlan, P.T., Lane, J., Moore, K.L., Aspen, J., Rycroft, J.A., \& O'Brien, D.C., 2000. The acute physiological and mood effects of tea and coffee: the role of caffeine level. Pharmacology, Biochemistry and Behavior, 66, 19-28. http://dx.doi.org/10.1016/S0091-3057(00)00192-1

Ritter, W., Simson, H., Vaughan, H. G., \& Friedman, D. (1979). A brain event related to the making of a sensory discrimination. Science, 203, 1358-1361. http://dx.doi.org/10.1126/science.424760

Smith, J. L., Johnstone, S. J., \& Barry, R. J. (2006). Effects of pre-stimulus processing on subsequent events in a warned Go/NoGo paradigm: Response preparation, execution and inhibition. International Journal of Psychophysiology, 61, 121-133. https://doi.org/10.1016/j.ijpsycho.2005.07.013

Steiner, G. Z., \& Barry, R. J. (2014). The mechanism of dishabituation. Frontiers in Integrative Neuroscience, 8, 14. https://doi.org/10.3389/fnint.2014.00014

Tabachnick, B. G., \& Fidell, L. S.( 2013). Using multivariate statistics (6th ed.). London: Pearson Education Limited.

Tieges, Z., Snel, J., Kok, A., \& Ridderinkhof, K. R. (2009). Caffeine does not modulate inhibitory control. Brain and Cognition, 69, 316-327. https://doi.org/10.1016/j.bandc.2008.08.001

Tucker, L. R. (1951). A Method for Synthesis of Factor Analysis Studies (Personnel Research Section Report No. 984). Washington, DC: Department of the Army.

VaezMousavi, S. M., Barry, R. J., Rushby, J. A., \& Clarke, A. R. (2007). Evidence for differentiation of arousal and activation in normal adults. Acta Neurobiologiae Experimentalis, 67, 179-186.

Vidal, F., Hasbroucq, T., Grapperon, J., \& Bonnet, M., (2000). Is the ‘error negativity’ specific to errors? Biological Psychology, 51, 109-128. https://doi.org/10.1016/S0301-0511(99)00032-0 
Wessel J. R. (2018). Prepotent motor activity and inhibitory control demands in different variants of the go/no-go paradigm. Psychophysiology, 55, e12871. https://doi.org/10.1111/psyp.12871

Zahn, T. P., \& Rapoport, J .L. (1987). Autonomic nervous system effects of acute doses of caffeine in caffeine users and abstainers. International Journal of Psychophysiology, 5, 33-41. https://doi.org/10.1016/0167-8760(87)90070-5 
Figure legends

Fig. 1. A recent updated version of the Child Processing Schema for the equiprobable Go/NoGo task (centre), with the associated processing stage markers (PCA-derived component headmaps) for Go (top) and NoGo (bottom), based on Barry et al. (2018). Early common stages of sensory processing and categorization lead to the separation of two processing streams. Note that pale font identifies components that are infrequently extracted in child data; their corresponding headmaps are also omitted, except for that of the NoGo fN2c which was extracted in Barry et al.'s (2018) sample.

Fig. 2. Panel A shows mean ERPs at the midline sites for Go and NoGo, with the major components labelled. Panel B shows Go ERPs for Caffeine and Placebo conditions; Panel C shows the corresponding NoGo waveforms. Panels D to F show the corresponding sets of virtual ERPs generated from the accepted PCA components.

Fig. 3. The Go component headmaps obtained under Caffeine and Placebo conditions, with their factor information and comparative measures of temporal $\left(\mathrm{r}_{\mathrm{c}}\right)$ and topographic $[\mathrm{r}(17)]$ congruence.

Fig. 4. The NoGo component headmaps obtained under Caffeine and Placebo conditions, with their factor information and comparative measures of temporal $\left(\mathrm{r}_{\mathrm{c}}\right)$ and topographic $[\mathrm{r}(17)]$ congruence.

Fig. 5. The revised Child Processing Schema modified to reflect the new findings from this study. Note the stimulus-specific indicators in the categorization components (N1-1 and PN), and the reclassification of the P1 and NoGo fN2c as robust components (indicated via bold font). 
Go

CATEGORIZATION

SENSORY PROCESSING

N1

$\mathrm{P} 1 \rightarrow \mathrm{N1-3} \rightarrow \mathrm{N1}-1 \rightarrow \mathrm{PN}$

SENSORY PROCESSING

NoGo

Go: RESPONSE EXECUTION

$\mathrm{P} 2 / \mathrm{N} 2$

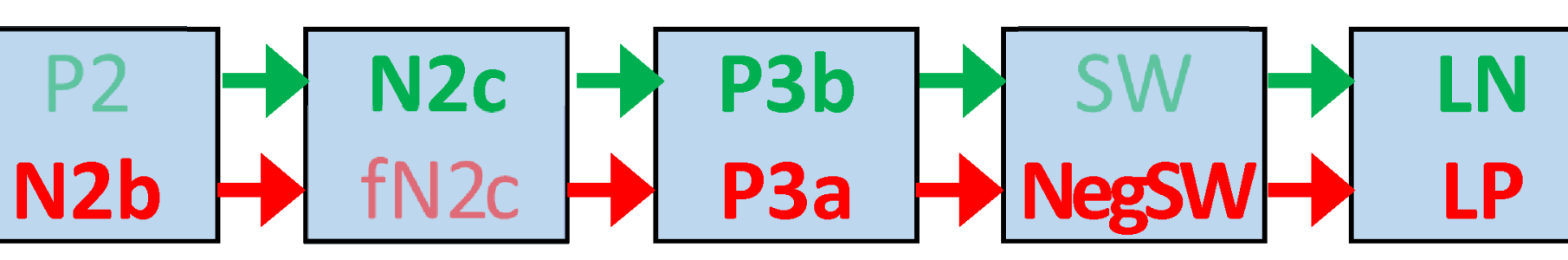

NoGo: TERMINATE PROCESSING
CATEGORIZATION

INHIBITION \& EVALUATION
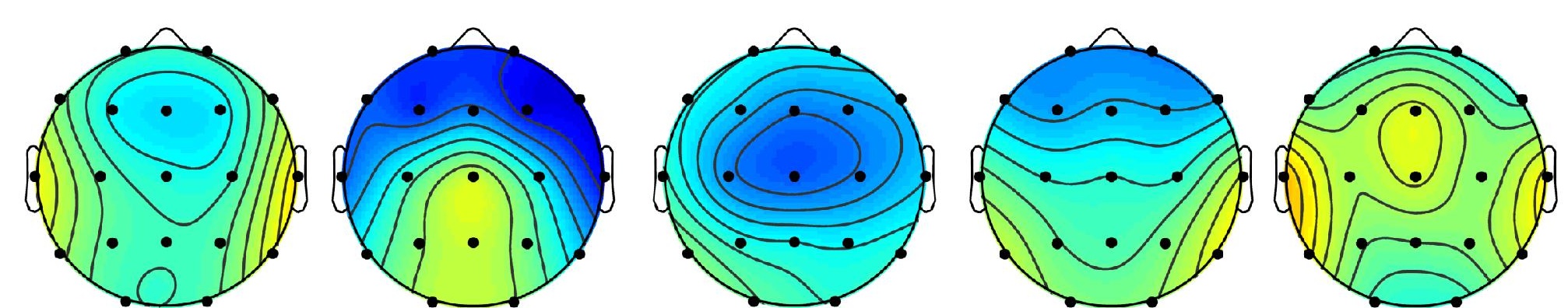
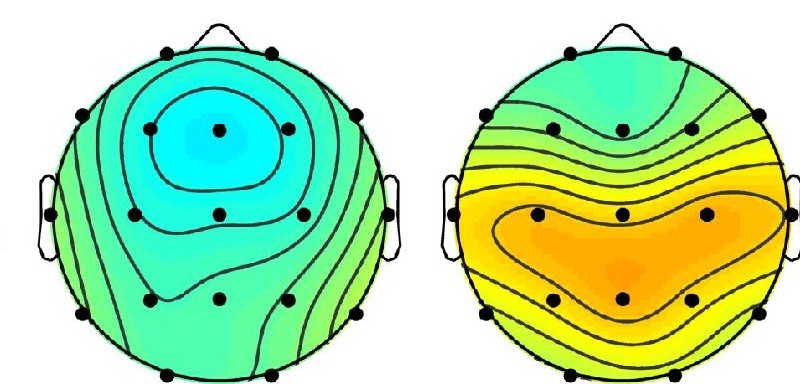
$\begin{array}{llllllll}\text { Latency } & 76.2 & 109.4 & 164.1 & 257.8 & 437.5 & 742.2 & \mathrm{~ms}\end{array}$ $\begin{array}{llllllll}\text { Variance } & 2.2 & 2.9 & 7.4 & 17.0 & 39.0 & 16.8 & \%\end{array}$

Caffeine
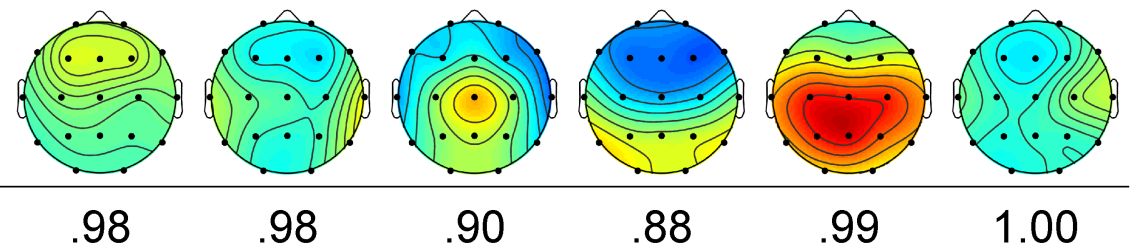

10 $r_{c}$

.98

.98

.90

.99

.95

Placebo

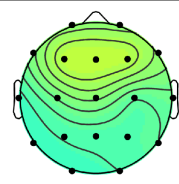

2.4

70.3

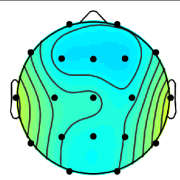

3.3

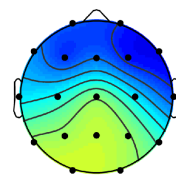

20.4

111.3

6

7
2

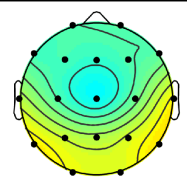

5.3

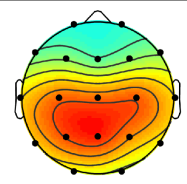

35.3

505.9

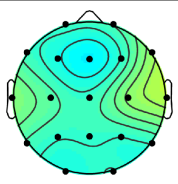

16.1
$-10$ $\mathrm{uV}$ $\%$

$734.4 \mathrm{~ms}$ 3 


\section{NoGo}

P1 N1-1

PN

N2b

fN2c

P3a

NegSW

LP

Factor

98

4

3

5

2

1

Latenc.

$\begin{array}{lll}70.3 & 107.4 & 146.5\end{array}$

209.0

279.3

5.0

$12.6 \quad 16.0$

9.5

472.7

$752.0 \mathrm{~ms}$

Variance

3.3
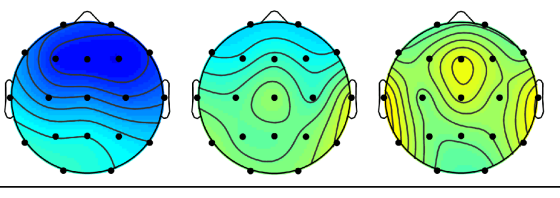

$$
r_{c}
$$

.96

.98

.89

.65

.93

.94

.77
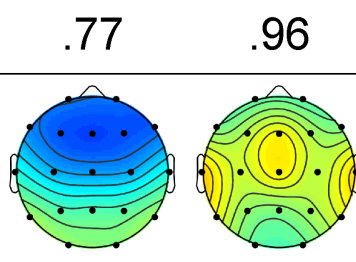

11.8

14.5

2.2

11.6

111.3

171.9

210.9

257.8

330.1

2

5
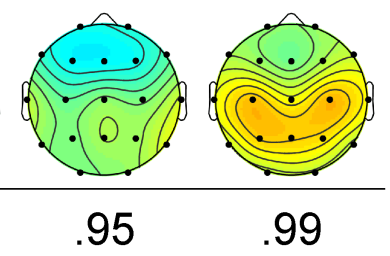

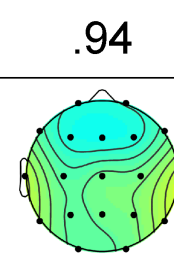

11.6
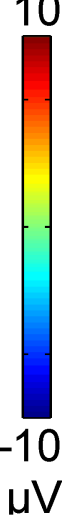

$\mu \mathrm{V}$
$\%$

$443.4 \quad 712.9 \mathrm{~ms}$ 1 


\section{CATEGORIZATION}

SENSORY PROCESSING

N1

$\frac{\text { P1 }}{\text { SENSORY PROCESSING }}$

CATEGORIZATION

\section{ACTIVATION \& EVALUATION}

Go: RESPONSE EXECUTION

$$
\text { P2/N2 }
$$

P300/LPC

PN

$\mathrm{N} 2 \mathrm{~b}$

\section{NoGo: TERMINATE PROCESSING}


Table 1. Behavioural outcomes [M (SD)]

\begin{tabular}{|c|c|c|c|c|c|c|}
\hline \multirow[b]{2}{*}{ Condition } & \multicolumn{3}{|c|}{ Go Error \% } & \multirow{2}{*}{$\frac{\text { NoGo Error \% }}{\text { Commissions }}$} & \multicolumn{2}{|c|}{ Go RT (ms) } \\
\hline & Omissions & Fast RT & Delayed RT & & Mean & Variability \\
\hline Placebo & $3.2(2.7)$ & $2.1(1.2)$ & $7.6(1.1)$ & $5.0(3.5)$ & 368.9 (39.7) & 83.0 (21.1) \\
\hline Caffeine & $1.8(1.2)$ & $2.1(1.7)$ & $7.2(1.2)$ & $4.2(2.8)$ & 353.9 (47.5) & $80.2(17.8)$ \\
\hline$t(23)$ & 2.44 & -0.01 & 1.05 & 0.95 & 1.88 & 0.61 \\
\hline$p$ (1-tailed) & .011 & .496 & .152 & .176 & .036 & .274 \\
\hline
\end{tabular}


Table 2. Go Component Statistics

\begin{tabular}{|c|c|c|c|c|c|c|c|c|c|c|c|c|c|c|c|c|c|c|}
\hline \multirow[b]{2}{*}{ Effects } & \multicolumn{3}{|c|}{ P1 } & \multicolumn{3}{|c|}{ N1-1 } & \multicolumn{3}{|c|}{ PN } & \multicolumn{3}{|c|}{ N2c } & \multicolumn{3}{|c|}{ P3b } & \multicolumn{3}{|c|}{ LN } \\
\hline & $F$ & $p$ & $\eta_{\mathrm{p}}^{2}$ & $F$ & $p$ & $\eta_{\mathrm{p}}^{2}$ & $F$ & $p$ & $\eta_{\mathrm{p}}^{2}$ & $F$ & $p$ & $\eta_{\mathrm{p}}^{2}$ & $F$ & $p$ & $\eta_{\mathrm{p}}^{2}$ & $F$ & $p$ & $\eta_{\mathrm{p}}^{2}$ \\
\hline$F>P$ & 33.36 & $<.001$ & .59 & 3.26 & .084 & .12 & 34.42 & $<.001$ & .60 & 81.19 & $<.001$ & .78 & 58.14 & $<.001$ & .72 & & & \\
\hline$C>F / P$ & 5.04 & .035 & .18 & 9.95 & .035 & .18 & & & & 25.24 & $<.001$ & .52 & 33.58 & $<.001$ & .59 & 12.58 & .002 & .35 \\
\hline $\mathrm{L}>\mathrm{R}$ & & & & & & & 52.56 & $<.001$ & .70 & & & & & & & 4.53 & .044 & .16 \\
\hline $\mathrm{M}>\mathrm{L} / \mathrm{R}$ & & & & & & & 45.59 & $<.001$ & .66 & 6.09 & .021 & .21 & & & & 8.69 & .007 & .27 \\
\hline $\mathrm{F}>\mathrm{P} \times \mathrm{L}<\mathrm{R}$ & & & & & & & 5.67 & .026 & .20 & & & & & & & & & \\
\hline $\mathrm{F}>\mathrm{P} \times \mathrm{M}<\mathrm{L} / \mathrm{R}$ & & & & 22.90 & $<.001$ & .50 & & & & 3.16 & .088 & .12 & 48.40 & $<.001$ & .68 & 13.35 & .001 & .37 \\
\hline $\mathrm{C}>\mathrm{F} / \mathrm{P} \times \mathrm{L}>\mathrm{R}$ & 5.00 & .035 & .18 & 8.96 & .007 & .28 & & & & & & & & & & 6.08 & .022 & .21 \\
\hline $\mathrm{C}>\mathrm{F} / \mathrm{P} \times \mathrm{M}>\mathrm{L} / \mathrm{R}$ & 3.66 & .068 & .14 & & & & 44.32 & $<.001$ & .66 & 10.15 & .004 & .31 & & & & 7.66 & .011 & .25 \\
\hline Caff $>$ Plac & & & & & & & & & & 8.61 & .007 & .27 & 6.92 & .015 & .23 & & & \\
\hline Caff $>$ Plac $\times$ F $>$ P & & & & & & & 27.05 & $<.001$ & .54 & 22.64 & $<.001$ & .50 & & & & & & \\
\hline Caff $>$ Plac $\times$ C $<$ F $/$ P & & & & 3.23 & .085 & .12 & & & & & & & & & & & & \\
\hline Caff $>$ Plac $\times$ L $>$ R & & & & & & & 9.36 & .006 & .29 & & & & & & & & & \\
\hline Caff $>$ Plac $\times$ M $>$ L $/$ R & & & & & & & 16.68 & $<.001$ & .42 & 5.41 & .029 & .19 & & & & & & \\
\hline Caff $>$ Plac $\times \mathrm{C}<$ F $/ \mathrm{P} \times \mathrm{L}<\mathrm{R}$ & & & & & & & & & & & & & & & & 3.11 & .091 & .12 \\
\hline Caff $>$ Plac $\times$ C $>$ F $/ \mathrm{P} \times \mathrm{M}<\mathrm{L} / \mathrm{R}$ & 7.64 & .011 & .25 & & & & 16.20 & .001 & .41 & & & & & & & & & \\
\hline
\end{tabular}

Note. Caff = caffeine; Plac = placebo; $\mathrm{F}=$ frontal; $\mathrm{P}=$ parietal $\mathrm{C}=$ central; $\mathrm{F} / \mathrm{P}=$ frontoparietal mean; $\mathrm{L}=$ left; $\mathrm{R}=$ right; $\mathrm{M}=$ midline; $\mathrm{L} / \mathrm{R}=$ hemispheric mean. Bold effects are significant and filled cells indicate a reversal of one relationship indicator in the corresponding effect. Two relationship reversals within an effect represents a statistically-equivalent effect (e.g., Caff $>$ Plac $\times \mathrm{C}<\mathrm{F} / \mathrm{P} \times \mathrm{M}<\mathrm{L} / \mathrm{R} \equiv$ Caff $>$ Plac $\times \mathrm{C}>\mathrm{F} / \mathrm{P} \times \mathrm{M}>\mathrm{L} / \mathrm{R}$ ). 
Table 3. NoGo Component Statistics

\begin{tabular}{|c|c|c|c|c|c|c|c|c|c|c|c|c|c|c|c|c|c|c|c|c|c|c|c|c|}
\hline \multirow[b]{2}{*}{ Effects } & \multicolumn{3}{|c|}{ P1 } & \multicolumn{3}{|c|}{ N1-1 } & \multicolumn{3}{|c|}{$\mathrm{PN}$} & \multicolumn{3}{|c|}{$\mathrm{N} 2 \mathrm{~b}$} & \multicolumn{3}{|c|}{$\mathrm{fN} 2 \mathrm{c}$} & \multicolumn{3}{|c|}{ РЗа } & \multicolumn{3}{|c|}{ NegSW } & \multicolumn{3}{|c|}{ LP } \\
\hline & $F$ & $p$ & $\eta_{\mathrm{p}}{ }^{2}$ & $F$ & $p$ & $\eta_{p}{ }^{2}$ & $F$ & $p$ & $\eta_{\mathrm{p}}{ }^{2}$ & $F$ & $p$ & $\eta_{\mathrm{p}}{ }^{2}$ & $F$ & $p$ & $\eta_{\mathrm{p}}{ }^{2}$ & $F$ & $p$ & $\eta_{\mathrm{p}}{ }^{2}$ & & & & & & \\
\hline $\mathrm{F}>\mathrm{P}$ & 64.90 & $<.001$ & .74 & 8.68 & .007 & .27 & 18.80 & $<.001$ & .45 & 34.23 & $<.001$ & .60 & 25.68 & $<.001$ & .53 & 5.98 & .023 & .21 & 11.00 & .003 & .32 & 34.90 & $<.001$ & .60 \\
\hline$C>F / P$ & & & & 5.37 & .030 & .19 & & & & 4.78 & .039 & .17 & & & & & & & 5.55 & .027 & .19 & 51.83 & $<.001$ & .69 \\
\hline $\mathrm{L}>\mathrm{R}$ & & & & & & & 16.78 & $<.001$ & .42 & 4.90 & .037 & .18 & & & & & & & 2.96 & .099 & .11 & & & \\
\hline $\mathrm{M}>\mathrm{L} / \mathrm{R}$ & 8.99 & .006 & .28 & 20.23 & $<.001$ & .47 & 89.03 & $<.001$ & .79 & & & & & & & 10.44 & .004 & .31 & & & & 25.08 & $<.001$ & .52 \\
\hline $\mathrm{F}>\mathrm{P} \times \mathrm{L}<\mathrm{R}$ & & & & & & & & & & & & & & & & & & & & & & 4.21 & .052 & .15 \\
\hline $\mathrm{F}>\mathrm{P} \times \mathrm{M}>\mathrm{L} / \mathrm{R}$ & & & & & & & 69.30 & $<.001$ & .75 & 5.06 & .034 & .18 & & & & 59.17 & $<.001$ & .72 & 4.71 & .041 & .17 & 46.42 & $<.001$ & .67 \\
\hline $\mathrm{C}>\mathrm{F} / \mathrm{P} \times \mathrm{L}>\mathrm{R}$ & 10.85 & .003 & .32 & 4.42 & .047 & .16 & & & & & & & 3.57 & .072 & .13 & & & & & & & & & \\
\hline $\mathrm{C}>\mathrm{F} / \mathrm{P} \times \mathrm{M}>\mathrm{L} / \mathrm{R}$ & 16.66 & $<.001$ & .42 & 4.45 & .046 & .16 & 4.88 & .037 & .18 & & & & & & & 8.49 & .008 & .27 & & & & 24.67 & $<.001$ & .52 \\
\hline Caff $>$ Plac & & & & & & & 4.45 & .046 & .16 & 15.68 & .001 & .41 & 5.71 & .025 & .20 & & & & & & & & & \\
\hline Caff $>$ Plac $\times$ F $>$ P & & & & & & & & & & 18.01 & $<.001$ & .44 & 14.58 & .001 & .39 & & & & 3.07 & .093 & .12 & & & \\
\hline Caff $>$ Plac $\times$ C $>$ F $/$ P & & & & 5.57 & .027 & .20 & & & & & & & 6.08 & .022 & .21 & 6.24 & .020 & .21 & & & & & & \\
\hline Caff $>$ Plac $\times$ L $>$ R & 8.02 & .009 & .26 & & & & 11.91 & .002 & .34 & & & & & & & & & & & & & & & \\
\hline Caff $>$ Plac $\times$ M $>$ L/R & & & & 16.14 & .001 & .41 & & & & 8.82 & .007 & .28 & 9.71 & .005 & .30 & & & & & & & 3.41 & .078 & .13 \\
\hline Caff $>$ Plac $\times$ F $>$ P $\times$ M $>$ L $/ \mathrm{R}$ & & & & & & & 25.93 & $<.001$ & .53 & & & & 14.73 & .001 & .39 & & & & & & & & & \\
\hline Caff $>$ Plac $\times$ C $<$ F $/$ P $\times$ L $>$ R & 4.30 & .049 & .16 & & & & & & & & & & & & & 5.26 & .031 & .19 & & & & & & \\
\hline Caff $>$ Plac $\times$ C $>$ F $/ \mathrm{P} \times \mathrm{M}>\mathrm{L} / \mathrm{R}$ & & & & 9.48 & .005 & .29 & & & & 5.11 & .034 & .18 & 8.30 & .008 & .27 & & & & & & & & & \\
\hline
\end{tabular}

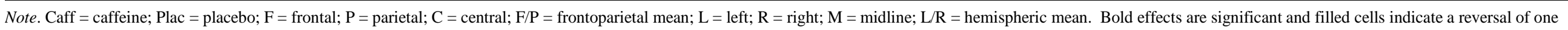
relationship indicator in the corresponding effect. Two relationship reversals within an effect represents a statistically-equivalent effect (e.g., Caff $>$ Plac $\times C<F / P \times M<L / R \equiv C$ aff $>$ Plac $\times C>F / P \times M>L / R)$. 